\title{
One Month Ongoing Intussusception: Case Report
}

\author{
Emrah Aydin \\ Pediatric Surgery Department, Bahcelievler State Hospital, Istanbul, Turkey \\ Email: dremrahaydin@yahoo.com
}

Received 29 December 2015; accepted 5 March 2016; published 8 March 2016

Copyright (C) 2016 by author and Scientific Research Publishing Inc.

This work is licensed under the Creative Commons Attribution International License (CC BY). http://creativecommons.org/licenses/by/4.0/

(c) (i) Open Access

\begin{abstract}
The aim is to present a case operated due to one-month ongoing intussusception and diagnosed as lymphoma. A six years old boy was admitted to our emergency department with complaint of colicky abdominal pain and bilious vomiting for the last month. He was operated due to $3 \mathrm{~cm}$ intussusception at ileocecal part. A mass which is about $6 \mathrm{~cm}$ in diameter, hard, partly mobile and invaginate the intestine at its posterior aspect was found. Pathology was reported as Burkitt lymphoma. He received two cycles of chemotherapy at post-operative period. He is still event free for the last two years. One must remember that lymphoma can be the lead point in intussusception especially in elderly children.
\end{abstract}

\section{Keywords}

\section{Intussusception, Burkitt's Lymphoma, Childhood}

\section{Introduction}

Intussusception is defined as invagination of a bowel segment one into another [1]. It is often presented between 3 - 18 months and occurs in 1 - 4 cases per 1000 live births [2] [3]. The male to female ratio is 3:2 [2] [3]. No underlying pathology can be detected before 2 years of age. However, there is frequently a "lead point" in patients older than 3 years old. Although it's rare, non-Hodgkin's lymphoma at terminal ileum and cecum may be the cause of intussusception. We presented a case who had recurrent intussusception for about a month and diagnosed as non-Hodgkin's lymphoma that located at cecum.

\section{Case Report}

Six-year-old male patient was admitted to our emergency department with intermittent colic, abdominal pain and bilious vomiting for a month. All laboratory examinations were normal which had been done in another 
center. At ultrasonography spontaneously reduced intussusception was diagnosed but no intervention was performed. In the physical examination, vital signs were stable on arrival in the emergency room and there was no external pathology seen on his body. No mass could be palpated but there was tenderness at right upper and lower quadrants of abdomen. All laboratory examinations were normal but mild leukocytosis. Abdominal gas distribution was normal at X-ray. Abdominal ultrasonography was reported as $3 \mathrm{~cm}$ intussusception located at with ileocecal. Nasogastric tube and rectal enema was performed for intestinal decompression. Because he had colicky abdominal pain at his follow up operation decision were taken. Pneumatic reduction was performed and no invaginated intestinal segment was seen but a large filling defect was founded at scope. Laparotomy was performed. An exploration was performed with right upper quadrant incision. There was no intussusception but edema and pseudo membrane covered mass at ileocecal region was found. There were lots of lymph nodes around mesenteric region. Approximately $6 \mathrm{~cm}$ in diameter, semi-mobile, hard mass found that invaginates the intestine at its posterior aspect (Figure 1). Ileoascendostomy and lymph node sampling was performed. The control laboratory values were within normal limits in the post-operative period. No additional pathology was detected in the thoracic and abdominal pelvic CT. At $5^{\text {th }}$ post-operative day nasogastric tube was taken and he started enteral feeding. He was discharged at $7^{\text {th }}$ post-operative day. Pathology was reported as Burkitt's lymphoma and reactive hyperplasia at lymph nodes. Immunohistochemical examinations were as CD20 (+), CD10 focal (+), CD3-reactive T lymphocytes (+), Pax5 (+), dt (-), EBV (-), CD21 (-) CD23 (-), MUM-1 (-), bcl-6 $(-)$, bcl-2 (-) and Ki-67 proliferative index was determined as $90 \%$. Scintigraphy of whole body scan was normal. Chemotherapy was performed for two cycles. He has been well and free of disease for the last two years.

\section{Discussion}

Intussusception is the second most common childhood abdominal emergency [1]. Only in 1.5\% - 12\% of cases underlying pathology can be found [4] [5]. These are Meckel's diverticulum, polyps, duplication, mesenteric cyst, intestinal hemorrhage and lymphoma [6]. Although it's rare, lymphoma because of its malignant nature is the most noticeable one and is "lead point" 6.5\% of intussusceptions [5]. Navarone et al. stated that accompanied by weight loss and long term complaints were the tips for gastrointestinal lymphoma [7]. In our case it was all for a month but he didn't lose any weight.

Burkitt's lymphoma constitutes about 40\% - 50\% of non-Hodgkin's lymphoma in childhood [8]. Patients often present with abdominal mass. Also abdominal pain, vomiting or sign and symptoms of intestinal obstruction due to mass effect or intussusception can be observed [9]. It's mostly seen age between 5 - 15 years [10]. Our patient was 6 years old and had abdominal pain and vomiting for about a month. Many ultrasonographies were performed and all reported spontaneously improved intussusception. His physical examination was consistent with acute abdomen. Pneumatic reduction was performed according to these findings. Even no intussusception was seen at pneumatic reduction because his clinical findings were consisted with intussusception he was operated.

$10 \%$ of non-Hodgkin's lymphoma cases are limited to the gastrointestinal tract [11]. Philips et al. stated that intestinal lymphoma may be associated with ulcerative colitis, chronic antigenic stimulation or Epstein-Barr virus in immune suppressed patients [12]. However, none of these factors was observed in our case.

Role of surgery in the treatment of Burkitt lymphoma is controversial. Burkitt's lymphoma originated from B lymphocytes serves very good response to combination chemotherapy. It was rapidly responsive and has prolonged remission [13]. But there are many opposing papers in the literature. Margrath et al. suggested removal

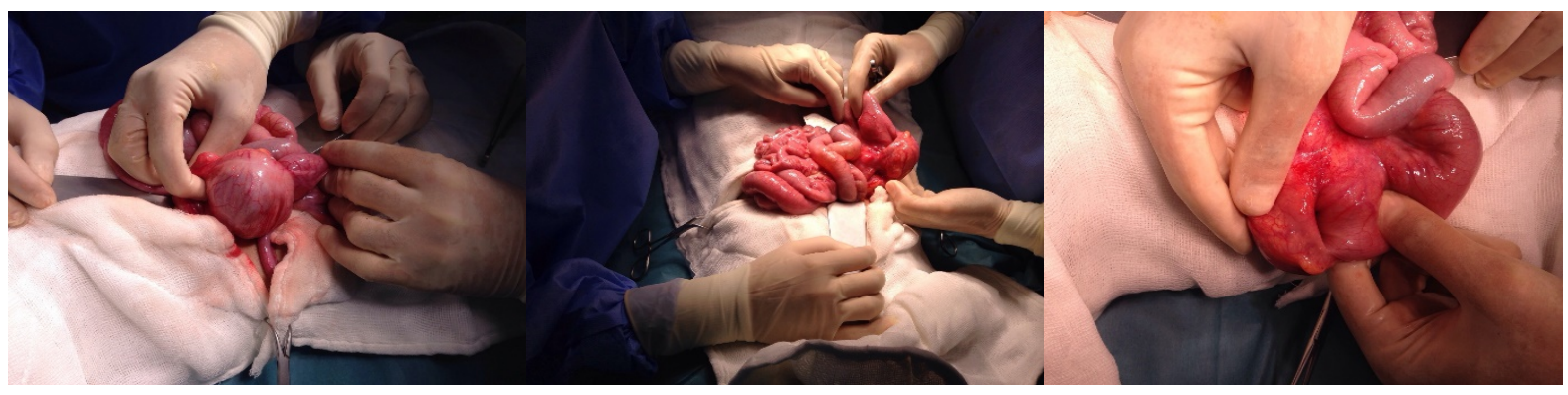

Figure 1. Per operative view of the mass. 
of more than $90 \%$ of the mass prior to chemotherapy at their Uganda based studies [14]. Our case was operated due to consisted acute abdomen findings at physical examination. Extensive resection was performed for preserving tumor free margins and lymph node sampling was performed for staging.

\section{Conclusion}

Treatment of intussusception should be individualized according to age and intestinal segment. Malignancy should be remembered especially later in childhood as a cause of intussusception and surgical treatment should always be kept in mind.

\section{References}

[1] Byrne, A.T., Geoghegan, T., Govender, P., et al. (2005) The Imaging of Intussusception. Clinical Radiology, 60, 39-46. http://dx.doi.org/10.1016/j.crad.2004.07.007

[2] DiFiore, J.W. (1999) Intussusception. Seminars in Pediatric Surgery, 8, 214-220. http://dx.doi.org/10.1016/S1055-8586(99)70029-6

[3] Simpson, T., Ivey, J. and Borkowski, S. (2004) Pediatric Management Problems. Intussusception. Pediatric Nursing, 30, 326-327.

[4] Ong, N.T. and Beasley, S.W. (1990) The Lead Point in Intussusception. Journal of Pediatric Surgery, 25, 640-643. http://dx.doi.org/10.1016/0022-3468(90)90353-B

[5] Blakelock, R.T. and Beasley, S.W. (1998) The Clinical Implications of Non-Idiopathic Intussusception. Pediatric Surgery International, 14, 163-167. http://dx.doi.org/10.1007/s003830050475

[6] Sorantin, E. and Lindbichler, F. (2004) Management of Intussusception. European Radiology, 14, $146-154$. http://dx.doi.org/10.1007/s00330-003-2033-2

[7] Navarro, O., Dugougeat, F., Kornecki, A., et al. (2000) The Impact of Imaging in the Management of Intussusception Owing to Pathologic Lead Points in Children. A Review of 43 Cases. Pediatric Radiology, 30, 594-603. http://dx.doi.org/10.1007/s002470000261

[8] Perkins, S.L. and Morris, S.W. (2007) Biology and Pathology pf Pediatric NHL. In: Weinsten, H.J., Hudson, M.M. and Link, M.P., Eds., Pediatric Lymphomas (Pediatric Oncology), Springer, New York, 101-106. http://dx.doi.org/10.1007/978-3-540-68753-5_6

[9] Sandlund, J.T., Downing, J.R. and Crist, W.M. (1996) Non-Hodgkin's Lymphoma in Childhood. The New England Journal of Medicine, 334, 1238-1248. http://dx.doi.org/10.1056/NEJM199605093341906

[10] Bethel, C.A., Bhattacharyya, N. and Hutchinson, C. (1997) Alimentary Tract Malignancies in Children. Journal of Pediatric Surgery, 32, 1004-1009. http://dx.doi.org/10.1016/S0022-3468(97)90387-0

[11] Herrmann, R., Panahon, A.M., Barcos, M.P., et al. (1980) Gastrointestinal Involvement in Non-Hodgkin’s Lymphoma. Cancer, 46, 215-222. http://dx.doi.org/10.1002/1097-0142(19800701)46:1<215::AID-CNCR2820460136>3.0.CO;2-6

[12] Philips, D.L., Keefe, E.B., Benner, K.G., et al. (1989) Colonic Lymphoma in the Transplant Patient. Digestive Diseases and Sciences, 34, 150-154. http://dx.doi.org/10.1007/BF01536173

[13] Wang, S.M., Huang, F.C., Wu, C.H., et al. (2010) Ileocecal Burkitt’s Lymphoma Presenting as Ileocolic Intussusception with Appendiceal Invagination and Acute Appendicitis. Journal of the Formosan Medical Association, 109, 476479. http://dx.doi.org/10.1016/S0929-6646(10)60080-0

[14] Magrath, I.T., Janus, C. and Dwards, B. (1984) An Effective Therapy for Both Undifferentiated (Including Burkitt's) Lymphomas and Lymphoblastic Lymphomas in Children and Young Adults. Blood, 63, 1102-1111. 